\title{
Endoscopic ultrasound-guided recanalization of complete pharyngoesophageal stenosis
}

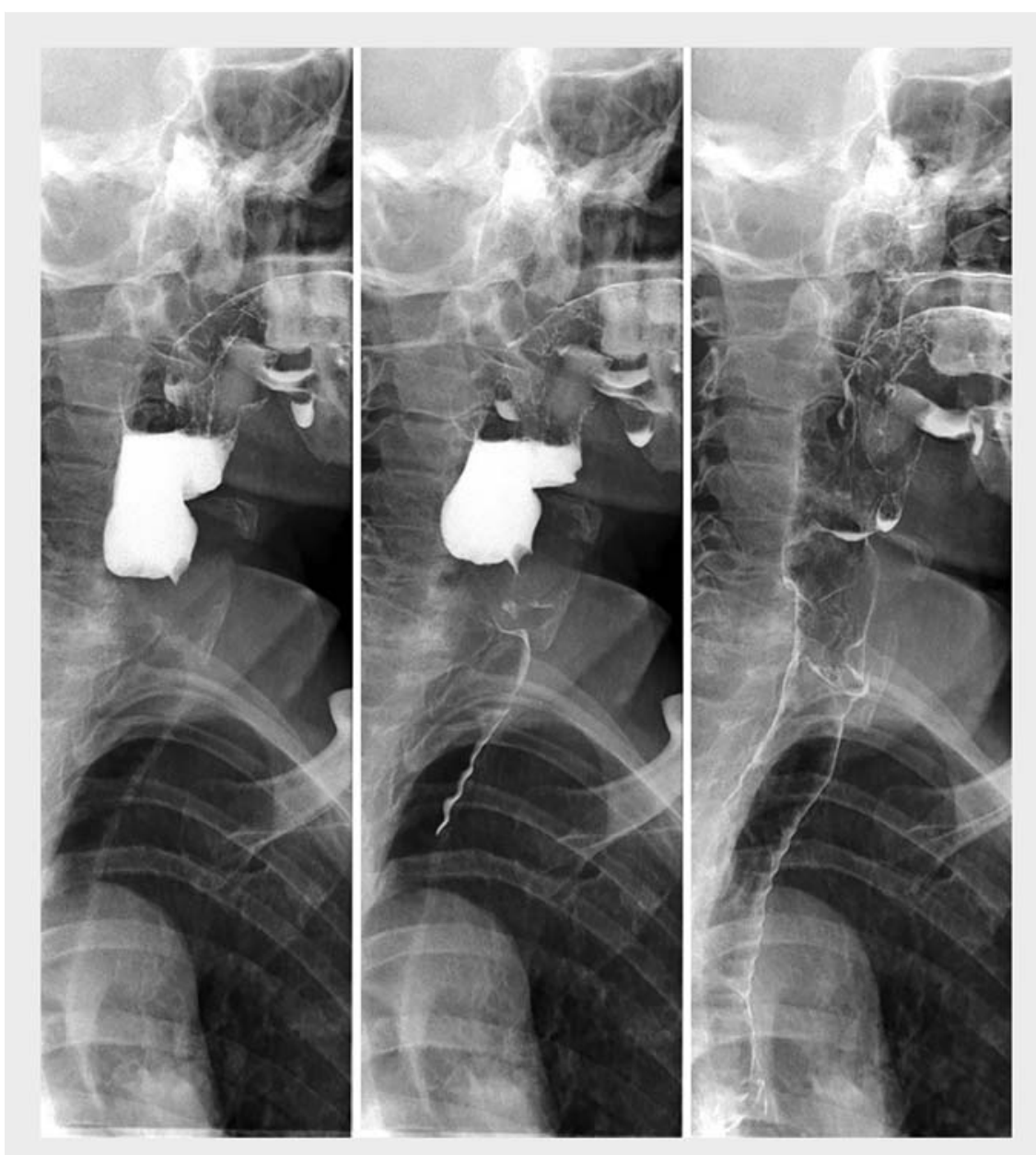

- Fig. 1 Esophagogram showing complete obstruction of the esophagus and passage of contrast into the airway.

A 74-year-old man was referred because of complete esophageal obstruction. He had a diagnosis of T3N1 hypopharyngeal squamous cell carcinoma and had undergone chemoradiotherapy with a complete response. He had a percutaneous endoscopic gastrostomy (PEG) for nutrition and had had aphagia for 18 months. Assessment of the stricture using contrast swallow demonstrated complete esophageal obstruction ( $\mathbf{F i g . 1}$ ), and combined anterograde (peroral) and retrograde endoscopy (through the feeding gastrostomy tract) revealed complete esophageal obstruction at the level of the upper esophageal sphincter ( $\mathbf{F i g . 2}$, - Fig.3). An attempt at rendezvous was unsuccessful [1].

We decided to perform the procedure guided by endoscopic ultrasound (EUS) ( Video 1). Through the PEG, a guidewire was advanced into the upper esophagus and an endoscopic retrograde cholangiopancreatography (ERCP) extractor balloon inserted over the guidewire. The balloon was filled with contrast to give a visible target on EUS. However, the balloon was not adequately identified with

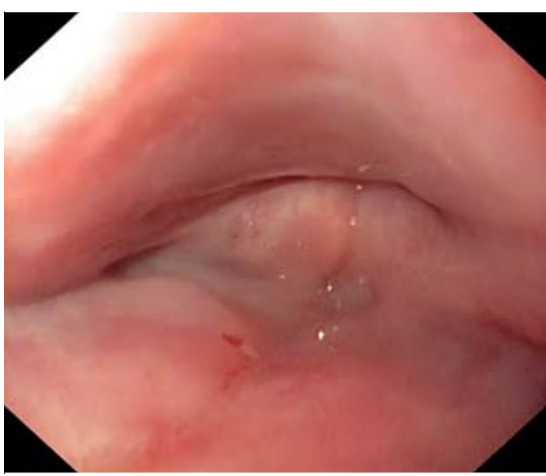

- Fig. 2 Peroral endoscopy. Complete obstruction at the upper esophageal sphincter.

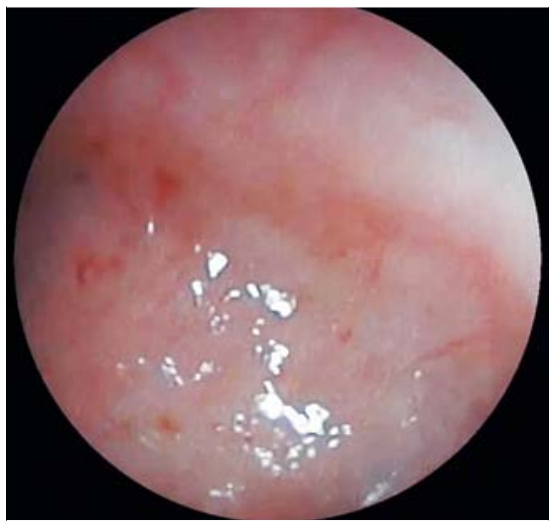

- Fig. 3 Retrograde endoscopy through the feeding gastrostomy tract. Complete obstruction in the upper esophagus.

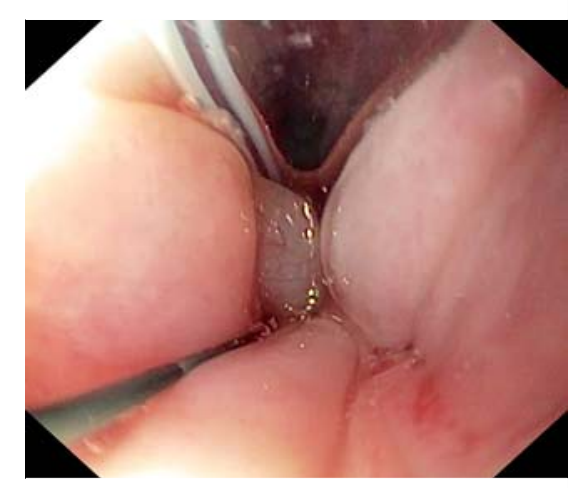

- Fig. 4 The guidewire passing into a suitable position in the esophagus. 


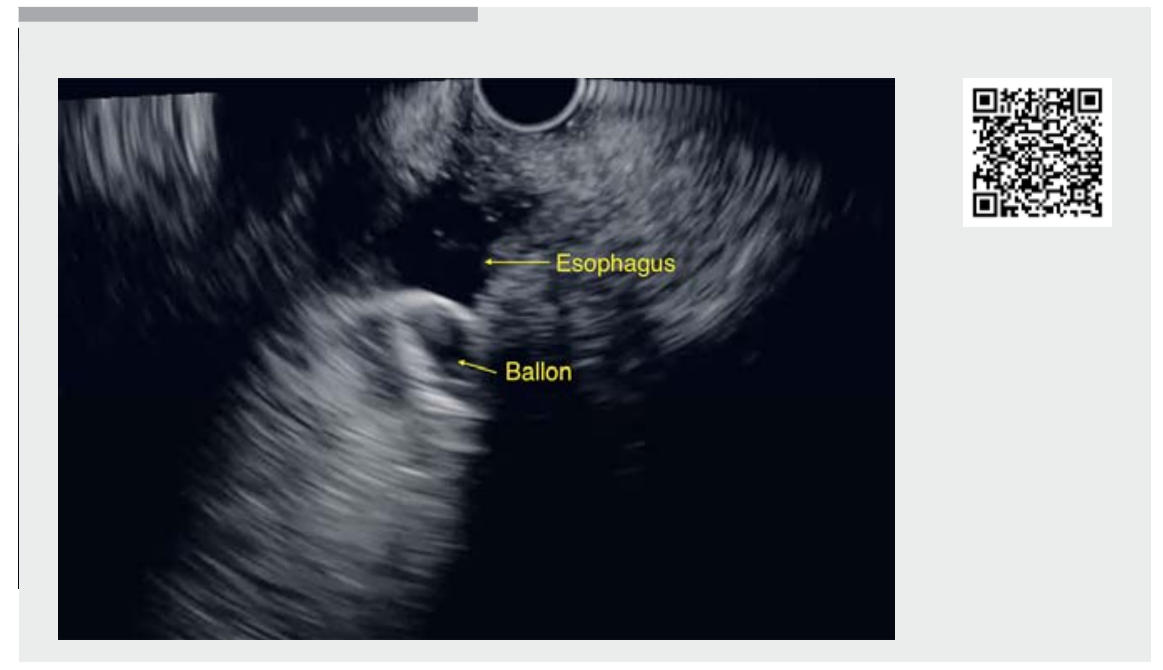

$\checkmark$ Video 1 Endoscopic ultrasound-guided recanalization of complete esophageal obstruction.

the echoendoscope positioned in the hypopharynx.

On fluoroscopy, a separation between the balloon and the echoendoscope was observed, by which contrast was introduced through the lumen of the balloon. EUS now showed a good target in the esophageal lumen. With a 19-G needle, the esophageal lumen was punctured and a 0.025 -inch Visiglide guidewire advanced. The echoendoscope was removed, and adequate positioning of the guidewire was verified with a gastroscope ( $\$$ Fig.4). A 6-Fr cystotome and a 6-mm dilation balloon were used to create a passage, followed by placement of a 12-Fr jejunal probe to keep the passage patent.

After 7 days, regular dilation sessions were started with Savary bougienage to $16-\mathrm{mm}$ in diameter. In two of the sessions, mitomycin was injected at the level of the stenosis. After 13 dilations, ade-
Corresponding author

\section{José R. Aparicio, MD, PhD}

Unidad de Endoscopia, Servicio de Medicina Digestiva, ISABIAL Hospital General Universitario de Alicante, Avda. Pintor Baeza s/n, 03013 Alicante, Spain

Fax: +34-96-5913629

japariciot@gmail.com

\section{Reference}

[1] Fusco S, Kratt T, Gani C et al. Rendezvous endoscopic recanalization for complete esophageal obstruction. Surg Endosc 2018; 32: 4256-4262

\section{Bibliography}

Endoscopy 2021; 53: E309-E310

DOI $10.1055 / a-1270-6704$

ISSN 0013-726X

published online 8.10 .2020

(C) 2020. Thieme. All rights reserved.

Georg Thieme Verlag KG, Rüdigerstraße 14,

70469 Stuttgart, Germany

Endoscopy_UCTN_Code_TTT_1AO_2AH

\section{Competing interests}

Dr. J. R. Aparicio is a consultant for Boston Scientific.

The authors

Belén Martínez-Moreno, Lucia Medina-Prado, Sandra Baile-Maxía, Carolina MangasSanjuan, Juan A. Casellas, José R. Aparicio Unidad de Endoscopia, Servicio de Medicina Digestiva, ISABIAL Hospital General Universitario de Alicante, Spain 